\title{
VARIEDADES CLÍNICAS DA MOLESTIA DE NICOLAS-FAVRE
}

\section{Resumo de uma conferencia realizada na Soc. Med. Cir. Campinas a 19 de junho de 1942 (*)}

\author{
DR. CARLOS DA SILVA LACAZ \\ (Assistente de Microbiologia da Fac. Med. São Paulo)
}

A molestia de Nicolas-Favre engloba hoje em dia grande numero de fórmas clínicas, razão pela qual Cerutti e Pavanati afirmam que ela deixou o campo restrito da venéreologia para invadir seáras alheias da medicina 'geral e da cirurgia. De acordo' com as conceṕçōes atuais a molestia de Nicolas FAVRe é uma infecção a virus, de natureza geral, e que apresenta especial afinidade para com as células do S. R. E., sendo pois uma retículo histiocitóse generalisada. A importancia médico social desta molestia é enorme. $\mathrm{Na}$ mulher, pelos sofrimentos físicos e morais que acarreta, a molestía de Nicolas-FAVRE iguala-se ao cancer e no homem, segundo MAY, todo o individuo portador desta doença deixa por assim dízer hipotecado o futuro do seu reto e dos seus órgãos genitais, pelas complicações que pódem advir, tais como elefantíase do penis e do escroto assim como a esclerose dos córpos cavernosos.

A molestia de NicolAS-FAVRe, tambem chamada quarta molestia venérea, bubão estrumoso, poroadenite inguinal, poroadenolinfite, lin-: fogranulomatose benigna, linfogranuloma venéreo, linfogranulomatose inguinal etc, individualisou-se como entidade mórbida perfeitamente definida na memoravel reunião dos médicos dos hospitais de Paris a 13 de janeiro de 1903.

A moléstia já era conhecida de Trousseau, Nelaton, ChassaiGNAC e outros.

A denominação de moléstia de Nicolas-Favre tem a vantagem de nada presupôr, ao mesmo tempo que se presta justa e merecida homenagem aos dois autores que perfeitamente a individualisaram.

Em 1922, orientada pelo prof. FAVRE, foi publicada a brilhante tése de Phylactos, abordando o assunto, e em 1925 Guglielmo Frei apresenta o seu téste biológico para dignóstico da referida molestia.

No capítulo da etiologia da molestia de Nicolas-FAvre muito concorreu para seu estudo a escola de Levaditi, provando que o ví-

(*) A presente palestra foi ilustrada com numerosos gráficos, diapositivos e gravuras. 
rus não tem o seu campo de ação limitado a um grupo de gânglios linfáticos inguinais, mas é capaz de agir sobre territorios diferentes do organismo animal, determinando quadros clínicos os mais polimorfos.

A escola franceza chefiada por Levaditi mostrou que o vírus da molestia de Nicolas-Favre determina no Macacus rhezus e cynomolgus lesões típicas de meningoencefalite, com a presença de infiltrados, nas meninges, de células endoteloides e elementos plasmáticos. $\mathrm{O}$ Chimpanzé (Troglodytes niger) é entre os antropoides, o mais apto a contrair a forma ganglionar da moléstia.

$\mathrm{O}$ vírus já foi inoculado no frepucio dum paralitico geral com o desenvolvimento de uma típica adenite inguinal linfogranulomatosa.

Entre nús numerosos trabalhos tenı sido publicados sobre o assunto, entre os quais os de Edmundo Vasconcelos, Luiz Batista, Fiquéne, Tibiriçá, Cotrim e outros.

Em 1940, em colaboração com BRESSAN conquistamos o premio Alves Lima com o trabalho "Contribuição para o estudo da molestia de Niconas-Favre em suas diferentes variedades clínicas".

\section{MODALIDADES CLINICAS DA MOLESTIA DE NICOLAS-FAVRE}

1 - Adenite inguinal - Nesses casos, o vírus penetra no organismo por um pequeno cancro que aparece alguns dias até três semanas após o coito suspeito. Este pequeno cancro (micro cancro poroadênico) ou úlcera ve:ıérea adenógena é muito pouco dermotrópico e polimorfo em sua apresentação. Cicatrísa-se facilmente sendo portanto difícil a verificação do acidenie primario. Por esta razão considera-se o período de incubação da molestia aquele que vae do coito infectante à adenite inguinal (25 a 30 dias). A adenite apresenta um período inicial com enfartamento dos gânglios inguinais, sendo muito frequente a adenopatia ilíaca, intra-abdominal. Após o período inicial segue-se o período de estadio e após, o período de supuração e fistulisação. Nesta fase a adenite é muito típica, pois a péle da região apresenta um aspecto característico, como ralo de um regador na expressão de RAMOND. O período final é de fibrose dos gânglios inguinais. Ao,lado da adenite, surge uma fenomenologia geral que consiste em fébre, cefaléa, artralgias e mialgias, inapetencia etc. O cancro linfogranulomatoso apresenta-se sob os tipos ulceroso, nodular, herpetiforme, papuloso e algumas vezes um cancro zigante (raro). Outras vezes a molestia se inicía com uma uretrite, uma linfangite troncular ou um edema do prepucio sem aparecimento do cancro poroadênico.

2 - Adenites extranguinais - A bibliografia médica refere diversos casos de adenites extra inguinais. Hellerström cita o caso de um cirurgião que acidentalmente feriu-se no dedo por ocasião de 
um ato operatorio e que dias após apareceu com uma adenite axilar, diagnosticada de natureza linfogranulomatosa por meio de varias reações e exames.

Cerutti e Pavanati em sua brilhante monografia "Linfogranulomatosi inguinale benigna" citam numerosos casos de adenites sub maxilares cuja porta de entrada foi a mucosa bucal. Quasi sempre estes pacientes contam em sua história mórbida relações línguo-vulvares. Entre nós, Ramos e Silva publicou interessante caso de adenite sub-maxilar de natureza linfogranulomatosa.

Myerson réfere-se à um caso de molestia de Nicolas-Favre com lesões na mucosa do palato mole, faringe e laringe.

3 - Adenopatia generalisada - Ha casos de molestia de Nicolas-F Avre com repercussão ganglionar generalisada. O diagnóstico diferencial tem que ser feito com a tuberculose ganglionar, sífilis, mal de Hodgkin, leucemia, retículo histiocitomas etc.

Próvas de laboratorio elucidarão o diagnóstico.

4 - Adenites com associação - Em certos casos associa-se à quarta molestia venérea, a sífilis, tuberculose ou o ulcus mole. São infecções simultâneas, que devem merecer a atenção cuidadosa do clínico para um completo êxito terapêutico. Entre nós, Sales GoMEs publicou um caso dessa natureza em que havia uma infecção poroadênoluética.

5 - Síndrome gênito-retal_linfogranulomatoso de Yersild ou síndrome reto=genital de Roeghalt - Grande numero de lesões se enquadram neste síndrome:

a) Estiomène ou ulcus vulvae cronicum, superficial, perfurante ou hipertrófico (HUGUier) com ou sem elefantíase:

b) Ano-retites linfogranulomatosas;

c) Vegetações mirtiformes de Simon;

d) Lesões associadas (fistulas, geralmente).

Bensaude e Lambling, estudando as ano-retites linfogranulomatosas afirmam que o conceito que os protologistas faziam anteriormente dos processos inflamatorios do reto modificou-se por completo após os conhecimentos sobre a molestia de Nicolas-Favre. Assim, o clássico sifiloma ano-retal de Fournier passou a ser considerado de origem linfogranulomatosa.

Segundo Tibiriçá a mucosa do reto é infectada de dentro para fóra e não de fóra para dentro como pensam diversos autores. Este autor poude demonstrar, a custa de exames anátomo-patológicos, que os gânglios peri-retais de GÉrota assim como a adventícia do reto são quasi sempre poupados o que não acontece com a mucosa e a submucosa.

Ao lado da retite, quasi sempre os pacientes apresentam prisão de ventre mais ou menos rebelde, dificuldades na defecação, modificações na fórma e calibre das fezes e disturbios consequentes à re- 
tenção de fezes no tubo digestivo. A função renal quasi sempre é prejudicada.

VASCONCELOS, que se preocupou com o estudo desse assunto entre nós, tendo sido mesmo relator oficial do tema "Retites estenosantes" ao $1 .^{\circ}$ Congresso de Cirurgia reunido no Rio de Janeiro, acha que quando a porta de entrada do vírus é representada pela mucosa vaginal, existem linfáticos diretos da vagina para o reto, de tal modo que o ultravírus é levado diretamente à submucosa retal e nesta parte é que as lesões se iniciaríam. Verifica-se igualmente que as lesões são mais frequentes ao nível da ampola retal. Compreende-se perfeitamente que a submucosa dessa região estando comprometida, a simples irritação fecal sobre a mucosa vai creando um terreno propício à ulceração. Estabelecendo-se a ulceração, sobrevém quasi sempre infecção secundaria e então a gordura peri retal aumenta consideravelmente comprimindo o reto e favorecendo a estenose. Verificou VASCONCELOS que si tal infecção secundaria fôr diminuida com o auxílio de lavagens e irrigações antiséticas diminue consideravelmente a gordura periretal.

Nos homens a retite estenosante quasi sempre é resultado da prática sodômica.

Outros autores pensam de modo um pouco diferente, achando que si o cancro poroadênico se processa na parede anterior da vagina o vírus seria drenado para os gânglios -da região ínguino-crural, e então estaríamos diante de um caso de adenite inguinal linfogranulomatosa; si o eancro se localizasse na parede posterior, os linfáticos drenariam o vírus para os gânglios periretais de GERótA e as lesốes caminhariam neste caso de fóra do reto para a mucosa; finalmente, si a lesão fôsse intraretal o vírus ganharía facilmente a submucosa e o processo se estendía; então, de dentro para fóra.

Entre nós. o quadro radiológico das retites estenosantes foi bem estudado por E. Cotrim.

Nas mulheres, quasi sempre à retite, se associam outras lesões, tais como fístulas reto vaginais, elefantíase da vulva, condilomas perianais, agravando consideravelmente o prognóstico.

6 - Perimetrites e anexites - Muitas perimetrites e anexites são de natureza linfogranulomatosa, conforme demonstraram os estudos de Barthels e Biberstein, entre outros. Morales acha que em certos casos de prolapso genital intervém um fator de órdem linfogranulomatosa, destruindo o Retinaculum uteri que constitue como sabemos o aparelho de sustentação e suspensão do útero, de tal modo que esta destruição favorece o prolapso genital.

De abcessos tubo ovarianos de natureza linfogranulomatosa já foram preparados antígenos de FREI que se mostraram altamente específicos e sensiveis.

7 - Epididimítes linfogranulomatosas - Waldemar Cortts, na Clínica do Prof. Bisouert (Santiago) reuniu em sua tése de Urologia varios casos de epididimítes linfogranulomatosas. Em 
colaboração com Ary Srqueira tivemos ocasião de observar interessante caso de epididimíte pelo vírus linfogranulomatoso e recentemente CAyres Brito comunicou à Sociedade Médica São Lucas um caso desta natureza.

8 - Localizações urétro vesicais - Uretrites linfogranulomatosas já tem sido descritas como pórta de entrada do vírus. Entre nós, Eugenio Mauro publicou algumas observações interessantes a respeito do assunto. Muitas vezes à uretrite segue-se uma orquiepididimite, tal como acontece em casos de blenorragia.

9 - Localizações articulares - Artralgias e mialgias já tem sido observadas no decurso da linfogranulomatose em sua forma inguinal classica. Nas monografias de Cerutti e Pavanati, de May e em nosso trabalho escrito em colaboração com BRESSAN existem citados diversos casos de verdadeiras poliartrites de tipo reumatismal em doentes portadores de molestia de Nicolas-Favre.

10 - Localizações endovenosas - Flebites já tem sido descritas como manifestações da molestia de Nicolas Favre, mas os casos observạdos são ainda em pequeno numero. A veia mais comumente comprometida é a fenural, talvez por propagação das lesões ganglionares.

11 - Localizações no neuro eixo - Kitagawa foi um dos primeiros pesquizadores que observou alterações liquóricas em casos de molestia de Nicolas Favre. Depois, diversos autores se dedicaram ao estudo do assunto, tendo HeCTOR CRUz publicado o resultado de suas observações, mostrando que o líquor se apresentava geralmente com uma hipertensão, aumento da albumina, glicose, uréia e linfócitos. Interessante notarmos que este líquor inoculado em ratinhos determinava nesses animais alterações humorais e tissulares as mais variadas possiveis, mas todas elas de natureza linfogranulomatosa.

Experimentalmente, verifica-se que o virus poroadênico apresenta grande atividade para com as celulas nervosas, reproduzindo-se com facilidade meningo-encefalites específicas. José MAY acredita na existencia de verdadeiras tabes e epilepsias de origem linfogranulomatosa. Estes dados nos mostram perfeitamente que o vírus da molestia de Nicolas Favre dissemina-se com facilidade em todo o organismo animal, particularmente no início da molestia.

12 - Manifestações oculares - Segundo Levaditr, o vírus linfọgranulomatoso pode se localizar primitivamente nos olhos ou ros seus anéxos, determinando tumefação das palpebras, infiltração das conjuntivas, proliferação folicular e enfartamento dos gânglios regionais. Possivelmente, o que os oftalmologistas denominam de conjuntivite de Parinaud e granuloma de Morax são manifestações oculares da molestia de NrCOLAS-FAVRE. Experimentalmente, conse- 
gue-se reproduzir particularmente em coelhos uma queratite linfogranulomatosa, e nas células da córnea pesquizam-se então os grânulocorpusculos de Mragawa.

As manifestações secundarias qu a o vírus da molestia de NicolasFAvre determina no aparelho ocular são as mais interessantes pussiveis e foram muito bem estudadas por Funakawa, Kitagawa, EspilDora Luque e recentemente por Vasquez Barriere e May. De um modo geral verifica-se edema da papila ótica acompanhada de dilatação e tortuosidade dos pequenos vasos mais visinhos a tla. VASQUEZ BARRIERE fazia sistematicamente em seus doentes um exáme biomicroscópico da córnea, conjuntiva, íris e cristalino, passando depois ao exame oftalmoscópico. A seguir, media a pressão arterial na arteria central da retina utilizando-se do oftalmodinamômeıro de BAILLIART assim como a medida da tensão ocular com o tonômetro de Schrötz. Este autor, ao lado do sinal de Kitagawa (edema peripapilar) constatou aumento de pressão da arteria central da retina em quasi todos os casos observados assim como diminuição da tensão do globo ocular. O edema peripapilar, dizem alguns autores, sería explicado pela hipertensão intracraneana ou liquórica, presente em quasi todos os casos ou a fenomenos de ordem tóxica, tais como retenção clorada, hiperpolipeptidemia ou então a reações meningéias aséticas devidas a lesões vasculares cerebrais.

Este assunto ainda merece ser melhor estudado e para a sua completa elucidação muito tem contribuido a escola médica uruguáia.

13 - Induratio penis plastica - A induratio penis plastica constitue a síndrome de La Peyronie ou síndrome de MAY e consiste na esclerose dos corpos cavernosos. Este sindrome acha-se hoje em dia vinculado em grande porcentagem de casos a uma origem linfogranulomatosa. $O$ tecido conjuntivo prolifera exuberantemente, processando-se reações fibroblásticas intensas. Em 85 casos de induratio 66 são de natureza linfogranulomatosa, na estatística coligida por MAY.

14 - Síndrome da retração palmar ou molestia de Dupuytren - A molestia de Dupurtren segundo MAy parece em alguns casos ser de natureza linfogranulomatosa. Com certa frequencia verifica-se associação da induratio penis plastica com a retração palmar. Trata-se de molestia relativamente rara, de começo insidioso, evolução progressiva e de histologia mais ou menos semelhante a dos queloides, sem sinais inflamatorios. Em um caso apresentado por MAY a reação de FREI era fortemente positiva.

15 - Elefantíase do penis e do escroto - A elefantíase consiste como tod.os sabemos em uma dilatação dos vasos linfaticos da pele acompanhada de fibrose. Quasi sempre os doentes com elefantíase peno escrotal contam um passado de adenite linfogranulomatosa com indurações escleróticas nos gânglios da região ínguino 
crural, de tal modo que se estabelecem correntes linfáuıas retrógradas que lentamente vão creando o processo de elefantíase. EDSON de Oliveira, Ramos e Silva já descreveram entre nós casos desta natureza.

16 - Linfangite troncular e edema do prepucio - A linfangite troncular pode se processar sob a forma de cordões ao redór do sulco bálano prepucial; outras vezes, constitue-se um nódulo ou mesmo coleções laterais ou posteriores com a formação de um edema prepucial. A linfangite nodular do dorso do penis é tambem frequente. Às vezes, a linfangite e o edema do prepucio determinam fimose e o penis adquite a forma de saxofone na expressão pitoresca de MAY; seria um estado de pré elefantíase.

17 - Eritema nodoso e eritema polimorfo - O eritema nodoso que aparece no decurso da linfogranulomatose quasi sempre é resultado de uma difusão hematogênica do vírus. Segundo FrnocCHIARo o eritema nodoso representa um fato secundario em indivíduos com especial hipersensibilidade cutânea.

18 - Outras lesões cutâneas linfogranulomatosas - MIDANo dividiu as lesões cutâneas de natureza linfogranulomatosa em varios tipos: papilomatosas, ulcerosas, ectimatiformes, pustulosas e dermo hipodermicas, podendo ainda ajuntar-se a estas, erupções escarlatiniformes e ulcerações da pele com formações quelóidianas.

19 - Lesões de órgãos abdominais - Nos casos de adenopatía ilíaca é comum uma reação peritoneal, um verdadeiro estado de peritonismo pélvico. Nos casos de adenite inguinal em sua fase inicial, ao lado de alterações hematológicas e liquóricas, provando que o vírus apresenta uma fase de disseminação hematogênica, observamos quasi sempre hépato e esplenomegalia. Lesões mono orgânicas de natureza linfogranulomatosa em visceras do abdomen ainda não foram descritas.

Numa visão muito rápida ficam aí estabelecidas as diferentes variedades clínicas da Molestia de Nicolas-Fayre, cujo interesse é 'enorme não só no ponto de vista médico como tambem social. A profilaxía desta molestia é dificílima particularmente depois que se demonstrou a existencia de mulheres portadoras de vírus sem lesões clínicas aparentes. São mulheres que contagiam facilmente. No Congo Belga, 43,5\% das prostitutas apresentam FREI positivo e em St. Louis $47,7 \%$. Por esses dados verifica-se a dificuldade de uma campanha profilática rigorosa. 


\section{Laboratorios de Suturas Cirurgicas Lida.}

Catgut - Seda - Linho - Agrafes, etc.

SANTO ANDRÉ - S. P. R. - São Paulo -- Brasil

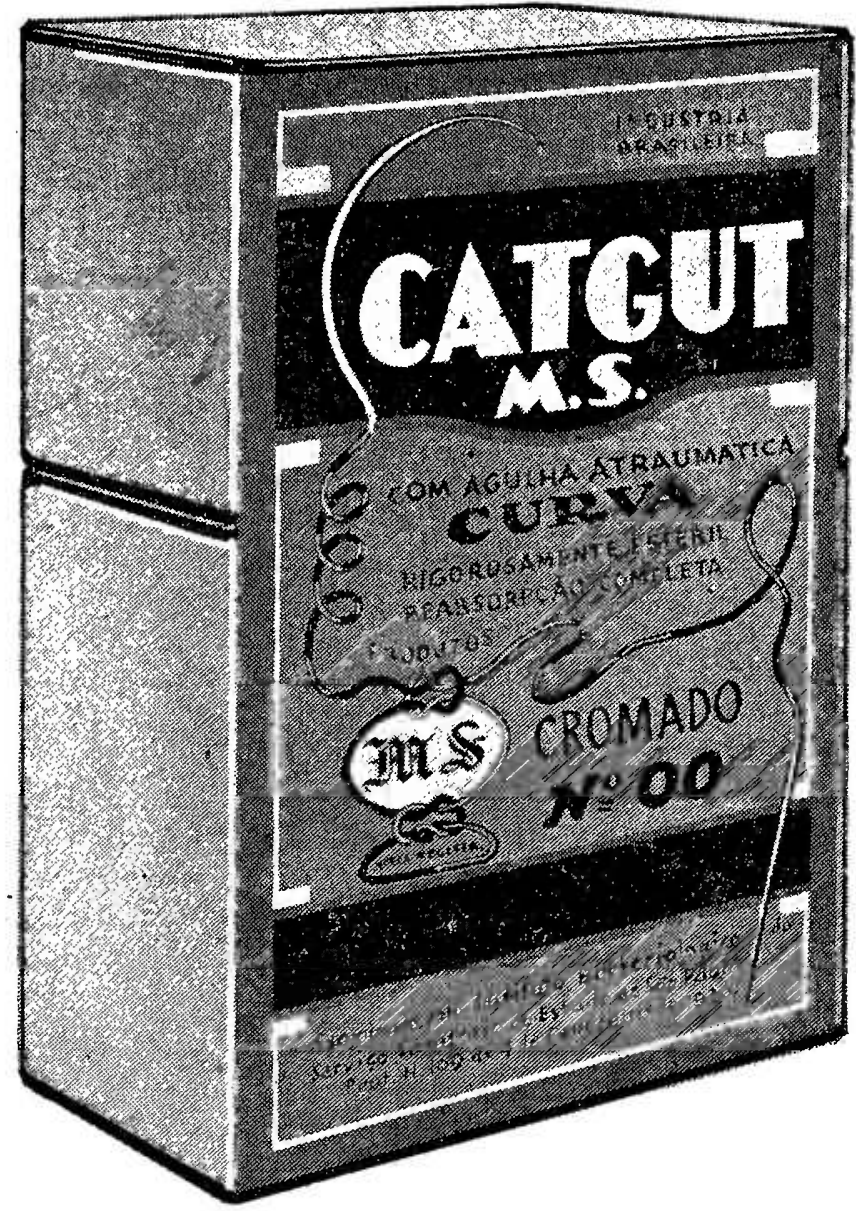

C A T G U T M. S. "A T R A"

Montado em agulhas atraumaticas inoxidaveis, CURVAS, SEMI-CURVAS e RETAS

Fios de 0,70, Simples ou cromado,

N. ${ }^{\circ} 000$

$" 00$

$", \quad 0$

REPRESENTANTE EM SÃO PAULO: Praça da Sé, 108 Sala 503 SAVERIO PEPI $\begin{gathered}\text { Fone }{ }^{\circ} \text { andar } \\ \text { - } 5279\end{gathered}$ 